\title{
Review
}

\section{Inspiratory Muscle Training in Patients With Heart Failure: What Is New? Systematic Review and Meta-Analysis}

\author{
Aline de Cassia Meine Azambuja, Luma Zanatta de Oliveira, Graciele Sbruzzi
}

Objective. The benefits of inspiratory muscle training (IMT) have already been demonstrated in patients with heart failure (HF), but the best mode of training and which patients benefit from this intervention are not clear. The purpose of this study was to review the effects of IMT on respiratory muscle strength, functional capacity, pulmonary function, quality of life, and dyspnea in patients with HF; IMT isolated or combined with another intervention (combined IMT), the presence of inspiratory muscle weakness, training load, and intervention time were considered.

Methods. The search included the databases MEDLINE, EMBASE, Cochrane Central Register of Controlled Trials, Physiotherapy Evidence Database, and LILACS database through September 2019. The review included randomized studies that assessed IMT in isolation or combined with another intervention-in comparison with a control group, a placebo, or another intervention-in patients with HF. Fourteen studies were included, 13 for meta-analysis (10 for isolated IMT and 3 for combined IMT).

Results. Isolated IMT demonstrated an increase in maximal inspiratory pressure (MIP) $\left(25.12 \mathrm{~cm} \mathrm{H} \mathrm{H}_{2} \mathrm{O} ; 95 \% \mathrm{CI}=15.29\right.$ - 34.95), 6-Minute Walk Test $(81.18 \mathrm{~m} ; 95 \% \mathrm{CI}=9.73-$ 152.63), maximum oxygen consumption (12 weeks: $3.75 \mathrm{~mL} / \mathrm{kg} / \mathrm{min} ; 95 \% \mathrm{CI}=2.98$ to $4.51)$, and quality of life $(-20.68 ; 95 \% \mathrm{CI}=-29.03$ to -12.32$)$. The presence of inspiratory muscle weakness, higher loads, and longer intervention times resulted in greater increases in MIP. IMT combined with another intervention demonstrated an increase only in MIP.

Conclusions. Isolated IMT resulted in an increase in inspiratory muscle strength, functional capacity, and quality of life. IMT combined with another intervention resulted only in a small increase in inspiratory strength. Isolated IMT with higher loads can be considered an adjuvant intervention, especially for those who do not adhere to conventional rehabilitation and who have respiratory muscle weakness.

Impact. A systematic review was necessary to review the effects of IMT on respiratory muscle strength, lung function, functional capacity, quality of life, and dyspnea in patients with HF. Various clinical issues important for a better training prescription were considered; these included whether the performance of the training IMT as a form of isolated training benefits patients with HF, whether the combination of IMT with another intervention has additional effects, whether any patient with HF can benefit from IMT (alone or combined with another intervention), and whether only patients who already have respiratory muscle weakness benefit. Also important was establishing which training load provides the best result and the best intervention time, so that health care can be provided more efficiently.

Lay Summary. For people with heart failure, IMT by itself, without being combined with other exercise, can improve ease of breathing, increase the amount of distance that they can walk, and improve quality of life. Inspiratory training with higher loads might be helpful for those with respiratory muscle weakness who are unable to do conventional exercise.
A.C.M. Azambuja, MSc, Postgraduate Program in Pneumological Sciences, Universidade Federal do Rio Grande do Sul, Porto Alegre, Brazil; and Postgraduate Program in Human Movement Sciences, Universidade Federal do Rio Grande do Sul.

L.Z. de Oliveira, MSc, Postgraduate Program in Pneumological Sciences, Universidade Federal do Rio Grande do Sul.

G. Sbruzzi, PT, ScD, Postgraduate Program in Pneumological Sciences, Universidade Federal do Rio Grande do Sul, R. Felizardo, 750, CEP: 90690-200, Porto Alegre RS, Brazil; and Postgraduate Program in Human Movement Sciences, Universidade Federal do Rio Grande do Sul. Address all correspondence to Dr Sbruzzi at: graciele.sbruzzi@ufrgs.br.

[Azambuja ACM, de Oliveira LZ, Sbruzzi G. Inspiratory muscle training in patients with heart failure: what is new? systematic review and meta-analysis. Phys Ther. 2020;100:2099-2109.]

(C) The Author(s) 2020. Published by Oxford University Press on behalf of the American Physical Therapy Association. All rights reserved. For permissions, please email: journals.permissions@oup.com

Published Ahead of Print: September 15, 2020

Accepted: June 28, 2020 Submitted: April 16, 2019 
A pproximately 6.5 million American adults over 20 years of age were diagnosed with heart failure

(HF) between 2011 and 2014. ${ }^{1}$ This disease causes a reduction in cardiac output and blood flow to the peripheral and respiratory muscles. These changes can result in muscle dysfunction leading to fiber atrophy (mainly type I) and weakness of the peripheral and respiratory muscles, and the latter is a predictor of mortality and survival in these patients. ${ }^{2,3}$ Thus, muscle weakness, often associated with dyspnea, can cause fatigue, reduced functional capacity, and increased exercise intolerance in these patients. ${ }^{4-7}$ In this sense, inspiratory muscle training (IMT) may be used as an adjunct intervention to improve cardiopulmonary capacity in these individuals. ${ }^{8,9}$ Recently, 2 systematic reviews were published on the effects of IMT in patients with HF. ${ }^{10,11} \mathrm{Wu}$ et $\mathrm{al}^{10}$ included 8 studies and found that IMT improved inspiratory muscle strength (MIP), pulmonary function, exercise tolerance, and quality of life while reducing dyspnea. Sadek et $\mathrm{al}^{11}$ included 7 studies and showed the benefit of IMT in MIP, functional capacity, and dyspnea.

However, both reviews included randomized controlled trials (RCTs) and nonrandomized studies in the same analysis, which is not the most appropriate, since these designs have distinct methodological characteristics, and the searches were performed only until 2016. Also, sensitivity analyses regarding important clinical issues for better training prescription were not performed; these encompassed the following questions: Does performing IMT as a form of isolated training benefit patients with HF? Does combining the IMT with another intervention have additional effects? Can any patient with HF benefit from IMT, either isolated or combined with another intervention, or can only patients who already have respiratory muscle weakness benefit? Which training load provides the best result, and what is the best intervention time? Therefore, this systematic review was necessary to review the effects of IMT on respiratory muscle strength, pulmonary function, functional capacity, quality of life, and dyspnea in patients with HF by considering these issues.

\section{Methods}

This systematic review was planned and conducted according to the Preferred Reporting Items for Systematic Reviews and Meta-Analyses Guideline and the Cochrane Collaboration. ${ }^{12}$ The protocol was registered in PROSPERO (CRD42017080339).

\section{Data Sources and Searches}

The searches were carried out in the following databases: MEDLINE (PubMed), LILACS database, Physiotherapy Evidence Database, EMBASE, and Cochrane Central Register of Controlled Trials, in addition to a manual search of the references of studies already published on the subject. The search was conducted in September 2019, and the search terms used individually or in combination included "heart failure" and "breathing exercises" as well as a specific filter for RCTs. ${ }^{13}$ There were no restrictions regarding year and language. The complete search strategy used for PubMed is shown in Supplementary Table 1.

\section{Eligibility Criteria}

The RCTs that evaluated the effects of IMT (isolated or in combination with another intervention-conventional rehabilitation or exercise) were compared with control groups, placebo, or another intervention in the treatment of patients with HF in both decompensation and outpatient care. The following outcomes were considered: respiratory muscle strength, pulmonary function, functional capacity (assessed by distance walked in the 6-Minute Walk Test [6MWT] and maximum oxygen consumption [ $\mathrm{Vo}_{2}$ peak]), quality of life (assessed with the Minnesota Living With Heart Failure Questionnaire), and dyspnea.

\section{Study Selection}

The titles and abstracts of all identified articles were independently assessed by 2 reviewers (A.C.M.A. and L.Z.O.) in duplicate. All abstracts that failed to provide sufficient information on the inclusion and exclusion criteria were selected for evaluation of the full text and were included according to the eligibility criteria. Disagreements among the reviewers were resolved by consensus.

\section{Data Extraction}

The data were extracted through a standardized form created by the authors themselves containing information regarding the methodological characteristics of the studies, participants, interventions, and outcomes. Disagreements were also resolved by consensus. The main outcome was respiratory muscle strength (through MIP and maximal expiratory pressure). Secondary outcomes were pulmonary function (through forced vital capacity [FVC] and forced expiratory volume in the first second $\left[\mathrm{FEV}_{1}\right]$ ), functional capacity (assessed with the 6MWT and $\mathrm{Vo}_{2}$ peak [in $\mathrm{mL} / \mathrm{kg} / \mathrm{min}$ ]), quality of life (assessed with the Minnesota Living With Heart Failure Questionnaire, where lower scores should be interpreted as higher quality of life), and dyspnea (assessed with the Borg Scale).

\section{Quality Assessment}

The risk of bias assessment was performed by 2 independent reviewers (A.C.M.A. and L.Z.O.) using the items established by the Cochrane Collaboration tool: ${ }^{12}$ generation of randomization sequence, concealment of allocation, masking of patients and therapists, masking of outcome assessors, description of losses and exclusions, and intention-to-treat analysis. Studies without a clear 
Inspiratory Muscle Training in Heart Failure

description of these items were considered unclear or uninformed.

The level of evidence was assessed using the Grading of Recommendations Assessment, Development and Evaluation (GRADE) approach. ${ }^{12}$ For each outcome, the quality of the evidence was based on 5 factors: risk of bias, inconsistency, indirect evidence, imprecision, and potential for publication bias, resulting in 4 levels of evidence quality: high, moderate, low, and very low. The evaluation was performed on https://gradepro.org.

\section{Data Synthesis and Analysis}

The meta-analysis was performed using the random effects model, and the measures of effect were calculated by the difference between the means and the SD of the difference between the means. A 95\% CI was considered significant. The statistical heterogeneity of the treatment effect in all studies was evaluated by the inconsistency test $\left(\mathrm{I}^{2}\right)$, in which values between $25 \%$ and $50 \%$ were considered as indicating moderate and high heterogeneity, respectively. Sensitivity analyses were performed considering the following characteristics: IMT isolated or combined with another intervention, inclusion of patients with or without inspiratory muscle weakness (MIP $<70 \%$ of the predicted value), ${ }^{14}$ load used in the IMT, and intervention time. All analyses were performed using Review Manager 5.3 software (The Nordic Cochrane Centre, The Cochrane Collaboration, Copenhagen, Denmark).

\section{Role of the Funding Source}

This study was funded in part by the Coordenação de Aperfeiçoamento de Pessoal de Nivel Superior. The funder played no role in the design, conduct, and reporting of this study.

\section{Results}

\section{Description of the Studies}

The search strategy resulted in 1746 articles, of which 35 studies were considered relevant for detailed analysis; 14 of these studies met the eligibility criteria and were included in the systematic review $(n=374)$, and 13 of these studies were included in the meta-analysis $(n=342)$ (Fig. 1). Stein et $\mathrm{al}^{15}$ provided the results of MIP expressed in different ways, therefore not allowing this study to be included in the meta-analysis.

Ten studies performed isolated IMT and compared it with control groups. ${ }^{14-23}$ Of these studies, 7 included individuals with inspiratory muscle weakness. ${ }^{7,14,18,20-23}$ Regarding the load, 6 studies used loads of up to $30 \%$ of MIP, ${ }^{14,17,18,20,22,23}$ 1 study used loads of up to $40 \%$ of MIP, ${ }^{12} 2$ studies used loads of $60 \%$ to $90 \%$ of MIP, ${ }^{19,22}$ and 1 study $^{18}$ used $100 \%$ for 10 maximal repetitions. Regarding the intervention time, 3 studies performed the training for a period of 4 to
6 weeks, ${ }^{16,18,20} 2$ studies performed it for 8 weeks, ${ }^{16,19}$ and 5 studies performed it for 12 weeks $^{14,20,22-24}$ (Tab. 1).

Four studies performed IMT combined with another intervention, 2 of which were combined with aerobic training, ${ }^{25,26} 1$ with peripheral resistance training, ${ }^{26}$ and 1 with neuromuscular electrical stimulation. ${ }^{27}$ Of the 4 studies, only 1 included patients with muscle weakness. ${ }^{26}$ Regarding load, 3 studies used loads of up to $30 \%$ of MIP ${ }^{26-28}$ and 1 study used a load of $60 \%$ of MIP. ${ }^{25}$ Regarding the intervention time, 3 were performed for 12 weeks $^{25,26,28}$ and 1 was performed for 8 weeks ${ }^{27}$ (Tab. 1). In addition, all studies included outpatients care.

\section{Risk of Bias}

Of the studies included, $35.7 \%$ presented random sequence generation, $14.3 \%$ reported concealment of the allocation, $21.4 \%$ had masking of patients and used the intention-to-treat principle for statistical analysis, and none of the studies reported masking of therapists, presenting a high risk of bias for these characteristics. Moreover, $42.9 \%$ were masked by the evaluators of the outcomes (moderate risk of bias), and $78.6 \%$ described losses in follow-up and exclusion, characterizing a low risk of bias Supplementary Table 2.

\section{Effects of Interventions}

Maximal inspiratory pressure. Of the 13 studies eligible for the meta-analysis, only 12 studies were included in the analysis of the effects of IMT on MIP $(n=374) \cdot{ }^{14,16-23,25-28}$ The study by Palau et $\mathrm{al}^{28}$ was excluded from this analysis because it presented only baseline values for MIP; it was therefore impossible to calculate the mean difference.

Nine studies evaluated isolated IMT, showing an increase of $25.12 \mathrm{~cm} \mathrm{H}_{2} \mathrm{O}$ in MIP (95\% CI = 15.29-34.95) compared with the control group..$^{14,16-23}$ Because of the high heterogeneity, 3 sensitivity analyses were performed: (1) analysis only of studies that included individuals with inspiratory muscle weakness, ${ }^{18,20-23}$ in which it was possible to observe an even greater increase in MIP of $31.89 \mathrm{~cm} \mathrm{H}_{2} \mathrm{O}(95 \% \mathrm{CI}=18.04-45.74)$ in relation to patients without inspiratory muscle weakness ${ }^{16,17,19}$ who had an increase of $14.47 \mathrm{~cm} \mathrm{H}_{2} \mathrm{O}(95 \% \mathrm{CI}=6.54-22.40)$; (2) analysis of the training load, in which studies that used a load of up to $40 \%$ of MIP had an increase of $24.62 \mathrm{~cm}$ $\mathrm{H}_{2} \mathrm{O}(95 \% \mathrm{CI}=11.82-37.41){ }^{14,16,17,19-22}$ and studies that used loads of $60 \%$ to $90 \%$ of MIP had an increase of $31.69 \mathrm{~cm} \mathrm{H}_{2} \mathrm{O}(95 \% \mathrm{CI}=4.68-58.71) ;^{21,23}$ and (3) analysis of the intervention time, in which studies performed for 6 to 8 weeks demonstrated an increase of $21.83 \mathrm{~cm} \mathrm{H}_{2} \mathrm{O}$ $(95 \% \mathrm{CI}=7.89-35.77),{ }^{16,20,22,23}$ and studies with 12 weeks of intervention had a greater increase, reaching $32.40 \mathrm{~cm}$ $\mathrm{H}_{2} \mathrm{O}(95 \% \mathrm{CI}=13.79-51.00)^{14,20,22,23}$ (Fig. 2). On the basis of the GRADE approach, the level of evidence for this result was considered to be very low (Tab. 2). 


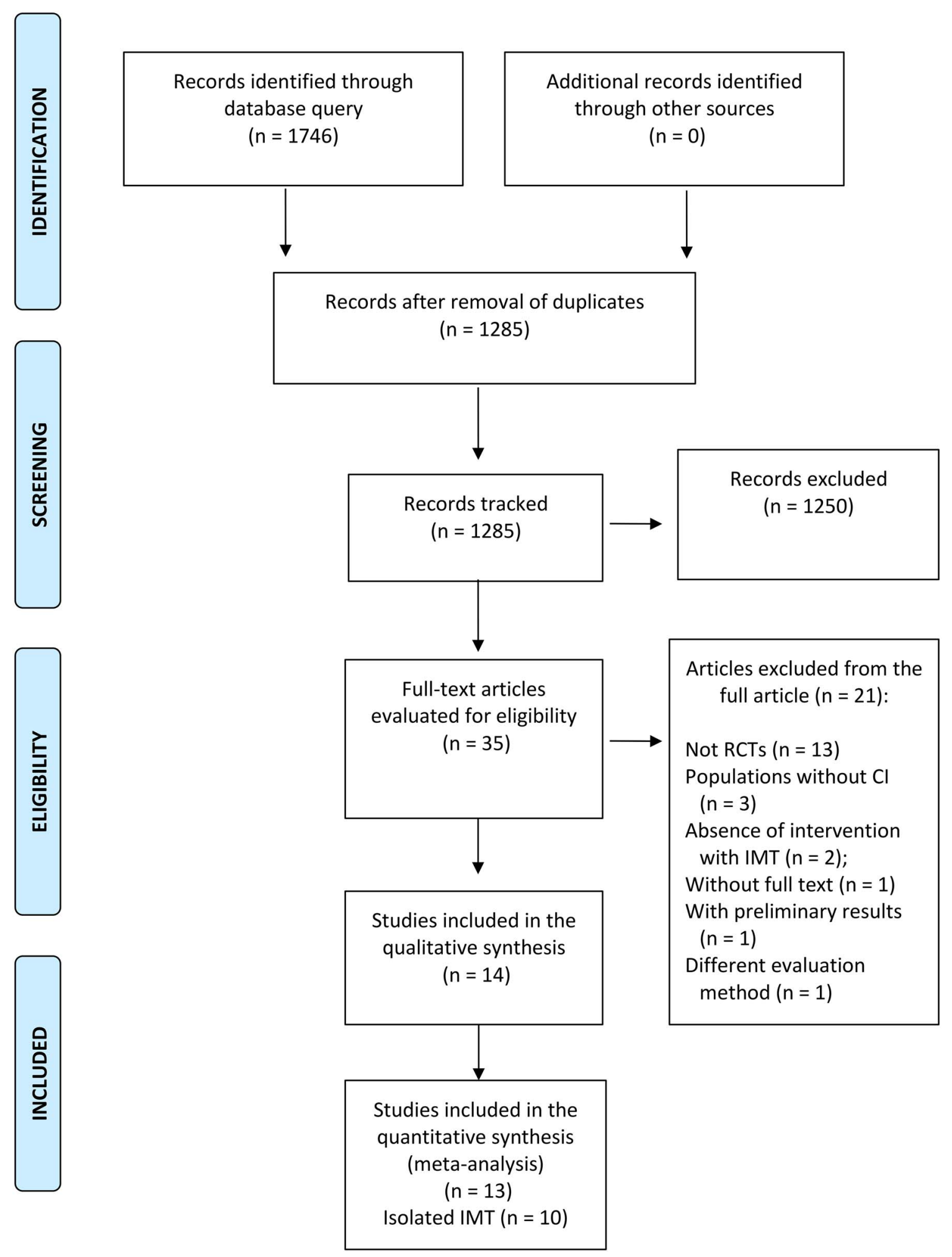

Figure 1.

PRISMA flow diagram. 
Inspiratory Muscle Training in Heart Failure

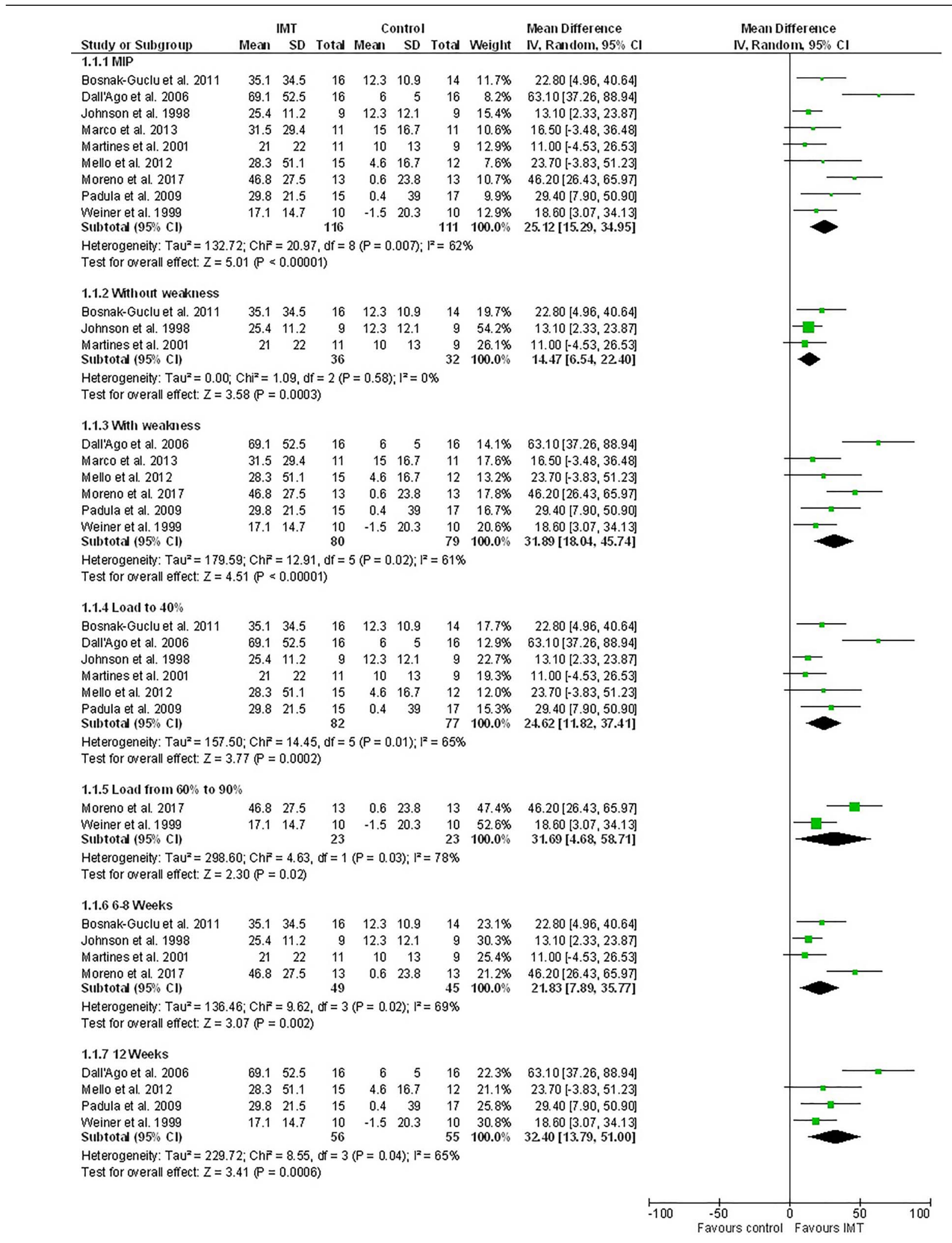

Figure 2.

Maximal inspiratory pressure for inspiratory muscle training (IMT) versus control group. 1.1.1 = IMT for all studies; $1.1 .2=$ studies without inspiratory muscle weakness; $1.1 .3=$ studies with inspiratory muscle weakness; $1.1 .4=$ studies with load of up to $40 \% ; 1.1 .5=$ studies with loads of $60 \%-90 \% ; 1.1 .6$ = studies conducted for $6-8$ weeks; $1.1 .7=$ studies conducted for 12 weeks. 


\section{Inspiratory Muscle Training in Heart Failure}

Table 1.

Characteristics of Studies ${ }^{a}$

\begin{tabular}{|c|c|c|c|c|c|c|}
\hline \multirow[b]{2}{*}{ IMT } & \multirow[b]{2}{*}{ Study (y) } & \multicolumn{2}{|c|}{ Methods } & \multirow[b]{2}{*}{$\begin{array}{l}\text { Characteristics } \\
\text { of Patients }\end{array}$} & \multicolumn{2}{|c|}{ Age, y, Mean (SD) } \\
\hline & & $\begin{array}{l}\text { Intervention } \\
\text { Group (No. of } \\
\text { Patients) }\end{array}$ & $\begin{array}{l}\text { Control Group } \\
\text { (No. of Patients) }\end{array}$ & & $\begin{array}{l}\text { Intervention } \\
\text { Group }\end{array}$ & Control Group \\
\hline \multirow[t]{10}{*}{ Isolated } & $\begin{array}{l}\text { Bosnak-Guclu } \\
\text { et al, }{ }^{16} 2011\end{array}$ & $\begin{array}{l}\text { IMT, } 40 \% \text { load; } \\
30 \mathrm{~min} / \mathrm{d}, 7 \\
\text { times/wk (16) }\end{array}$ & $\begin{array}{l}\text { IMT, placebo, } 15 \% \\
\text { load; } 30 \mathrm{~min} / \mathrm{d}, 7 \\
\text { times/wk (14) }\end{array}$ & $\begin{array}{l}\text { Functional class: } \\
\text { NYHA II or III } \\
\text { Stable outpatients }\end{array}$ & $69.5(8)$ & $65.7(10.5)$ \\
\hline & $\begin{array}{l}\text { Dall'Ago et al, }{ }^{14} \\
2006\end{array}$ & IMT, 30\% load (16) & $\begin{array}{l}\text { IMT without } \\
\text { inspiratory load } \\
\text { (16) }\end{array}$ & $\begin{array}{l}\text { Outpatient } \\
\text { individuals }\end{array}$ & $58(2)$ & $54(3)$ \\
\hline & $\begin{array}{l}\text { Johnson et al, }{ }^{17} \\
1998\end{array}$ & IMT, 30\% load (9) & $\begin{array}{l}\text { IMT, placebo, } 15 \% \\
\text { load (9) }\end{array}$ & $\begin{array}{l}\text { NYHA II or III } \\
\text { Stable individuals }\end{array}$ & $70(4.6)$ & $63.4(4.5)$ \\
\hline & Marco et al, ${ }^{18} 2013$ & $\begin{array}{l}\text { Inspiratory pressure } \\
\text { that allowed } 10 \\
\text { consecutive } \\
\text { maximal repetitions } \\
\text { (11) }\end{array}$ & $\begin{array}{l}\text { IMT, placebo, } 10 \% \\
\text { load (11) }\end{array}$ & $\begin{array}{l}\text { NYHA II or III } \\
\text { Stable individuals }\end{array}$ & $68.5(8.88)$ & $70.1(10.8)$ \\
\hline & $\begin{array}{l}\text { Martinez et al, }{ }^{19} \\
2001\end{array}$ & IMT, 30\% load (11) & $\begin{array}{l}\text { IMT, minimum load } \\
\text { of } 10 \%(9)\end{array}$ & $\begin{array}{l}\text { NYHA II or III } \\
\text { Stable individuals }\end{array}$ & $60(14)$ & $57(13)$ \\
\hline & Mello et al, ${ }^{20} 2012$ & IMT, 30\% load (15) & IMT, no load (12) & NYHA II & $54.3(2)$ & $53.3(2)$ \\
\hline & $\begin{array}{l}\text { Moreno et al, }{ }^{21} \\
2017\end{array}$ & IMT, 60\% load (13) & No training (13) & NYHA II or III & $61(14)$ & $60(13)$ \\
\hline & Padula et al, 222009 & IMT, 30\% load (15) & $\begin{array}{l}\text { Standard education } \\
\text { protocol (17) }\end{array}$ & $\begin{array}{l}\text { NYHA II or III } \\
\text { Stable individuals }\end{array}$ & $76(28)$ & $73(47)$ \\
\hline & Stein et al, ${ }^{15} 2009$ & IMT, 30\% load (16) & IMT, no load (16) & & NR & NR \\
\hline & Weiner et al, ${ }^{23} 1999$ & IMT, 15\% load (10) & IMT, placebo (10) & NYHA II or III & $66.2(4.6)$ & $63.8(4.0)$ \\
\hline \multirow[t]{4}{*}{$\begin{array}{l}\text { Combined } \\
\text { with another } \\
\text { intervention }\end{array}$} & $\begin{array}{l}\text { Adamopoulos } \\
\text { et al, }{ }^{25} 2014\end{array}$ & $\begin{array}{l}\mathrm{IMT}, 60 \% \text { load }+ \\
\text { aerobic training } \\
(21)\end{array}$ & $\begin{array}{l}\text { IMT, placebo, } 10 \% \\
\text { load + aerobic } \\
\text { training (22) }\end{array}$ & NYHA II or III & $57.8(11.7)$ & $58.3(13.2)$ \\
\hline & $\begin{array}{l}\text { Kawauchi et al, }{ }^{27} \\
2017\end{array}$ & $\begin{array}{l}\text { IMT, } 30 \% \text { load for } \\
\text { moderate intensity } \\
\text { and } 15 \% \text { load for } \\
\text { low intensity }+ \\
\text { peripheral } \\
\text { resistance training } \\
\text { (13) }\end{array}$ & Control (9) & NYHA II or III & $56(7)$ & $56(7)$ \\
\hline & $\begin{array}{l}\text { Winkelmann et al, } \\
2009\end{array}$ & $\begin{array}{l}\mathrm{IMT}, 30 \% \text { load }+ \\
\text { aerobic exercise } \\
\text { training (12) }\end{array}$ & $\begin{array}{l}\text { Aerobic exercise } \\
\text { training (12) }\end{array}$ & Stable individuals & $54(12)$ & $59(9)$ \\
\hline & Palau et al, ${ }^{28} 2018$ & $\begin{array}{l}\text { IMT, } 25-30 \% \text { load } \\
\text { +NMES in bilateral } \\
\text { quadriceps, } 400 \mu \mathrm{s} \\
\text { and } 10-50 \mathrm{~Hz}(13)\end{array}$ & $\begin{array}{l}\text { IMT, } 25-30 \% \text { load } \\
\text { (13) }\end{array}$ & NYHA III or IV & $73(10)$ & $75(10)$ \\
\hline
\end{tabular}

${ }^{a} \mathrm{IMT}=$ inspiratory muscle training; NMES = neuromuscular electrical stimulation; NR = not reported; NYHA = New York Heart Association.

Three studies that assessed IMT combined with another intervention were evaluated. ${ }^{23,24}$ It was observed that MIP increased by $11.08 \mathrm{~cm} \mathrm{H}_{2} \mathrm{O}(95 \% \mathrm{CI}=2.14-$ 20.01) in relation to the control group. When considering only the 2 studies that included individuals without inspiratory muscle weakness ${ }^{25,27}$ for the sensitivity analysis, the increase in MIP was $17.36 \mathrm{~cm}$ $\mathrm{H}_{2} \mathrm{O}(95 \% \mathrm{CI}=1.77-32.96)$. Most studies also used training loads of $30 \%$. When analyzing only these studies, ${ }^{26,27}$ a nonsignificant increase of $13.05 \mathrm{~cm} \mathrm{H}_{2} \mathrm{O}$ (95\% CI $=-3.40-29.51)$ was observed. Finally, 2 studies performed IMT for 12 weeks and obtained a nonsignificant increase of $9.23 \mathrm{~cm} \mathrm{H}_{2} \mathrm{O}(95 \% \mathrm{CI}=-0.21-$ 18.67) ${ }^{25,26}$ (Fig. 3). On the basis of the GRADE approach, the level of evidence for this result was considered low (Tab. 2). 
Table 2.

Quality of Evidence ${ }^{a}$

\begin{tabular}{|c|c|c|c|c|c|c|c|c|}
\hline IMT & $\begin{array}{l}\text { Measure of } \\
\text { Result }\end{array}$ & $\begin{array}{l}\text { No, of } \\
\text { Studies }\end{array}$ & $\begin{array}{l}\text { Risk of } \\
\text { Bias }\end{array}$ & Inconsistency & Indirectness & Imprecision & $\begin{array}{l}\text { Absolute Mean } \\
\text { Difference } \\
(95 \% \mathrm{Cl})\end{array}$ & $\begin{array}{l}\text { Quality of } \\
\text { Evidence }\end{array}$ \\
\hline \multirow[t]{5}{*}{ Isolated } & $\begin{array}{l}\text { Maximal } \\
\text { inspiratory } \\
\text { pressure }\end{array}$ & 9 & Serious $^{b}$ & Very serious $^{c}$ & Not serious & Not serious & $\begin{array}{c}25.12 \\
(15.29-34.95)\end{array}$ & Very low \\
\hline & $\begin{array}{l}\text { 6-Min Walk } \\
\text { Test }\end{array}$ & 3 & Serious $^{b}$ & Serious $^{c}$ & Not serious & Very serious $^{e}$ & $\begin{array}{c}81.18 \\
(9.73-152.63)\end{array}$ & Very low \\
\hline & $\mathrm{Vo}_{2}$ peak & 5 & Serious $^{b}$ & Very serious $^{c}$ & Not serious & Not serious & $2.21(0.1-4.51)$ & Very low \\
\hline & Quality of life & 2 & Very serious $^{b}$ & Serious $^{d}$ & Not serious & Serious $^{e}$ & $\begin{array}{c}20.68 \\
(29.03-12.32)\end{array}$ & Very low \\
\hline & Dyspnea & 2 & Serious $^{b}$ & Very serious $^{c}$ & Not serious & Not serious & $1.11(2.97-0.75)$ & Very low \\
\hline \multirow[t]{4}{*}{$\begin{array}{l}\text { Combined } \\
\text { with another } \\
\text { intervention }\end{array}$} & $\begin{array}{l}\text { Maximal } \\
\text { inspiratory } \\
\text { pressure }\end{array}$ & 3 & Serious ${ }^{b}$ & Not serious & Not serious & Serious $^{c}$ & $\begin{array}{c}11.08 \\
(2.14-20.01)\end{array}$ & Low \\
\hline & $\begin{array}{l}\text { Maximal } \\
\text { expiratory } \\
\text { pressure }\end{array}$ & 2 & Serious ${ }^{b}$ & Not serious & Not serious & Serious $^{c}$ & $\begin{array}{c}18.24 \\
(5.73-42.22)\end{array}$ & Low \\
\hline & $\begin{array}{l}\text { 6-Min Walk } \\
\text { Test }\end{array}$ & 2 & Serious $^{b}$ & Not serious & Not serious & Very serious $^{c}$ & $\begin{array}{c}42.5 \\
(17.91-102.92)\end{array}$ & Very low \\
\hline & $\mathrm{Vo}_{2}$ peak & 3 & Serious $^{b}$ & Not serious & Not serious & Not serious & $0(0.32-0.31)$ & Moderate \\
\hline
\end{tabular}

${ }^{a} \mathrm{IMT}=$ inspiratory muscle training; $\mathrm{Vo}_{2}$ peak = maximum oxygen consumption .

${ }^{b}$ Methodological limitation.

${ }^{c}$ High heterogeneity.

${ }^{d}$ Moderate heterogeneity.

${ }^{e}$ Large $\mathrm{Cl}$.

Maximal expiratory pressure. Two studies that compared IMT combined with another intervention with control groups evaluated maximal expiratory pressure and obtained a nonsignificant increase of $18.24 \mathrm{~cm} \mathrm{H} \mathrm{H}_{2} \mathrm{O}(95 \%$ $\mathrm{CI}=-5.73$ to 42.22$){ }^{26,27}$ Only 1 study that compared isolated IMT with the control group evaluated maximal expiratory pressure, and it was not possible to perform a meta-analysis of maximal expiratory pressure (Supplementary Fig. 1). ${ }^{16}$ On the basis of the GRADE approach, the level of evidence for this result was considered low (Tab. 2).

Functional capacity: 6MWT. Three studies evaluated isolated IMT and used a training load of up to $40 \%$ of MIP. $^{14,16,19}$ When analyzing these studies, an increase of $81.18 \mathrm{~m}$ in the 6MWT $(95 \% \mathrm{CI}=9.73-152.63)$ was observed. Because of the moderate heterogeneity, a sensitivity analysis was performed based on the study of Dall'Ago et al, ${ }^{14}$ which included individuals with inspiratory muscle weakness. Thus, heterogeneity was reduced to $0 \%$, but there was no significant difference in outcome ( $29.01 \mathrm{~m}$; 95\% CI $=-58.26$ to 116.27 ) (Fig. 4). On the basis of the GRADE approach, the level of evidence for this result was considered to be very low (Tab. 2).
Two studies performed combined IMT and used loads of $30 \% .{ }^{26,27}$ When observing these studies, there was a nonsignificant increase of $42.50 \mathrm{~m}$ in the 6MWT $(95 \%$ $\mathrm{CI}=-17.91$ to 102.92 ) compared with the control group (Supplementary Fig. 2). On the basis of the GRADE approach, the level of evidence for this result was considered to be very low (Tab. 2).

Functional capacity: $\mathrm{Vo}_{2}$ peak. In relation to Vo 2 peak, 5 studies that performed isolated IMT versus control evaluated this outcome, but there was no significant difference between groups $(2.21 \mathrm{~mL} / \mathrm{kg} / \mathrm{min} ; 95 \%$ $\mathrm{CI}=-0.10$ to 4.51$) \cdot{ }^{14,18-20,23} \mathrm{~A}$ sensitivity analysis that only assessed the studies that included individuals with inspiratory muscle weakness found no significant difference $(2.41 \mathrm{~mL} / \mathrm{kg} / \mathrm{min}$; $95 \% \mathrm{CI}=-0.03$ to 4.86$) .{ }^{15,19,23}$ A significant increase in this outcome $(3.75 \mathrm{~mL} / \mathrm{kg} / \mathrm{min}$; $95 \%$ CI $=2.98-4.51$ ) was observed only in the studies that performed training for 12 weeks (Supplementary Fig. 3). ${ }^{14,20}$ On the basis of the GRADE approach, the level of evidence for this result was considered to be very low (Tab. 2).

The 3 studies that performed combined IMT versus control for 12 weeks evaluated $\mathrm{Vo}_{2}$ peak but did not 


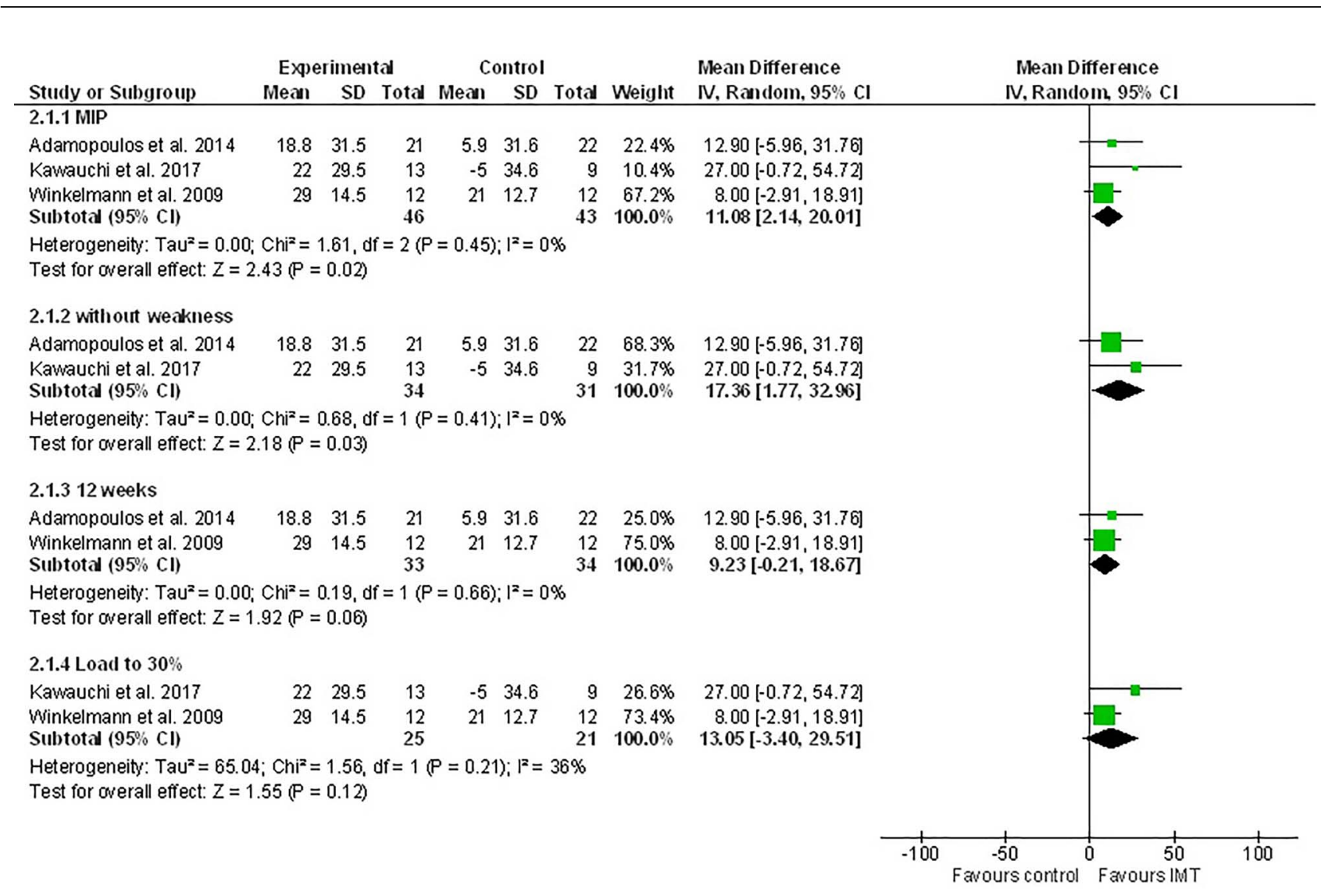

Figure 3.

Maximal inspiratory pressure for combined inspiratory muscle training (IMT) versus control group. 2.1.1 = IMT for all studies; $2 \cdot 1 \cdot 2=$ studies without inspiratory muscle weakness; 2.1.3 = studies conducted for 12 weeks; $2.1 .4=$ studies with load of up to $30 \%$.

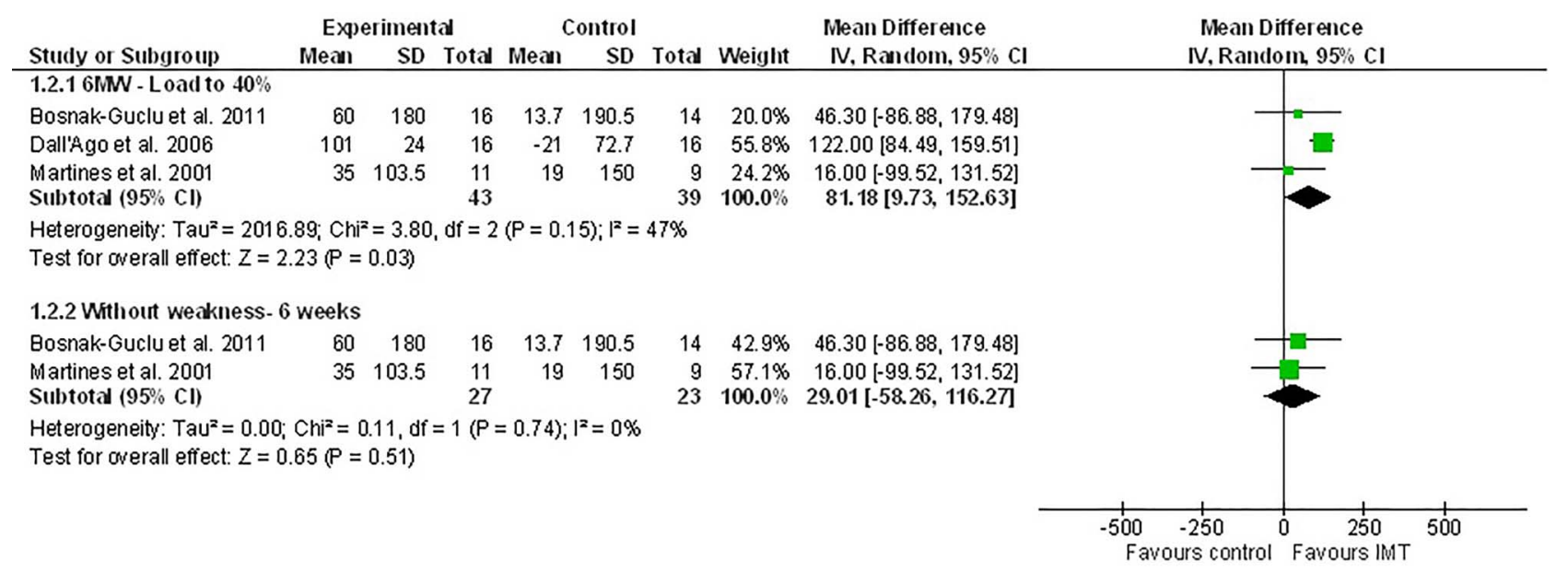

Figure 4.

Distance walked in the 6-Minute-Walk Test for inspiratory muscle training (IMT) versus control group. 1.2.1 = distance walked in the 6-Minute-Walk Test for all studies; 1.2.2 = distance walked in the 6-Minute-Walk Test for studies conducted with patients who were given IMT and had no inspiratory muscle weakness for 6 weeks. 
observe an increase $(-0.00 \mathrm{~mL} / \mathrm{kg} / \mathrm{min} ; 95 \% \mathrm{CI}=-0.32$ to $0.31),{ }^{25,26,28}$ and the same result was found when analyzing only the 2 studies that used loads of up to $30 \%$ (Supplementary Fig. 4). ${ }^{26,28}$ On the basis of the GRADE approach, the level of evidence for this result was considered moderate (Tab. 2).

Quality of life. Two studies performed isolated IMT. A decrease in MLHQF score of -20.68 (95\% CI $=-29.03$ to -12.32) was observed, indicating improvement in quality of life. ${ }^{14,20}$ Both studies included individuals with inspiratory muscle weakness and performed the intervention for 12 weeks (Supplementary Fig. 5). On the basis of the GRADE approach, the level of evidence for this result was considered to be very low (Tab. 2).

Four studies performed combined IMT versus control, with no significant difference in this outcome $(-5.04 ; 95 \%$ $\mathrm{CI}=-11.78$ to 1.70$).^{24-27}$ The same behavior was observed in the sensitivity analyses in relation to the use of loads of $30 \%(-1.07 ; 95 \% \mathrm{CI}=-13.01 \text { to } 10.86)^{26-28}$ and the intervention time for 12 weeks $(-4.89 ; 95 \% \mathrm{CI}=-11.88$ to $2.101)^{23,24,26}$ (Supplementary Fig. 6). On the basis of the GRADE approach, the level of evidence for this result was considered moderate (Tab. 2).

Dyspnea. Two studies performed isolated IMT versus control and assessed dyspnea, but no significant reduction was observed in this outcome $(-1.11 ; 95 \% \mathrm{CI}=-.97$ to 0.75) (Supplementary Fig. 7). ${ }^{14,16}$ On the basis of the GRADE approach, the level of evidence for this result was considered to be very low (Tab. 2).

Only 1 study that performed combined IMT versus control assessed dyspnea. ${ }^{26}$ The authors found a significant reduction of dyspnea in the intervention group compared with the control group.

Pulmonary function. It was not possible to perform a meta-analysis for any variables related to pulmonary function because of the lack of data or units of measurement.

Four studies evaluated pulmonary function through the FEV $_{1} /$ FVC outcome. ${ }^{16,21,23,25,27}$ Of these, $2^{16,21}$ performed isolated IMT and the meta-analysis was not performed, since 1 of the studies ${ }^{20}$ did not present postintervention values, making it impossible to analyze a single study. ${ }^{16}$ The study by Bosnak et $\mathrm{al}^{16}$ presented a reduction in $\mathrm{FEV}_{1} / \mathrm{FVC}$ ratio in the intervention group and increase in the control group after 6 weeks of intervention.

The other 2 studies that evaluated this outcome performed combined IMT. ${ }^{25,27}$ The study by Adamopoulos et $\mathrm{al}^{25}$ found no significant improvement after 12 weeks of intervention, and neither did the study by Kawauchi et $\mathrm{al}^{27}$ after 8 weeks of intervention.

FEV $_{1}$ and FVC were assessed by 3 studies. ${ }^{16,23,25}$ Two performed isolated IMT. ${ }^{16,23}$ The studies by Bosnak et al $^{16}$ and Weiner et $\mathrm{al}^{23}$ found no significant difference in the increase in $\mathrm{FEV}_{1}$ and FVC compared with the intervention and control groups. One study performed combined IMT and obtained a reduction in $\mathrm{FEV}_{1}$ and FVC in the intervention group (IMT plus aerobic training) and an increase in the control group (aerobic training). ${ }^{26}$

\section{Discussion}

The results from our pooled analyses indicate that isolated IMT resulted in an increase in inspiratory muscle strength, functional capacity, and quality of life, and this increase was higher in studies that included patients with respiratory muscle weakness who used training loads higher than $60 \%$ and who had longer intervention times. However, the IMT, when performed in combination with another intervention, demonstrated only a small increase in respiratory muscle strength.

As noted in this study, the improvement in inspiratory muscle strength promoted by isolated IMT may aid in the application of the improved functional capacity, as the respiratory muscle fatigue and dyspnea presented by these patients are associated with a low functional capacity. ${ }^{29,30}$

Still, the use of IMT with progressive inspiratory loads attenuates the respiratory muscle metaboreflex in patients with heart failure. The attenuation of the respiratory muscle metaboreflex subsequently improves perfusion to limb muscles during exercise by preventing the redistribution of blood flow to the inspiratory muscles. ${ }^{31,32}$ Furthermore, IMT can attenuate peripheral chemoreflex response and improve cardiac function, which is directly combined to a reduction in sympathetic excitation in patients with HF, improving systemic vasodilation and peripheral muscle perfusion while increasing ventilatory efficiency and, subsequently, functional capacity. ${ }^{33}$

It was also observed in the studies performed by Sbruzzi et $\mathrm{al}^{34}$ and $\mathrm{Wu}$ et $\mathrm{al}^{10}$ that isolated IMT improves the quality of life of patients with $\mathrm{HF}$, as measured with the Minnesota Living With Heart Failure Questionnaire. This improvement may be related to the benefits of IMT in cardiovascular and respiratory response and reduced perception of dyspnea, ${ }^{14}$ especially in individuals with inspiratory muscle weakness, since respiratory muscle strength may be an independent predictor of prognosis in patients with $\mathrm{HF}^{2}$

Dyspnea was not significantly modified after intervention with isolated IMT in this review. Some factors may explain this result: the 2 studies included used low IMT loads (loads $<60 \%$ of MIP), and 1 of the studies performed the 


\section{Inspiratory Muscle Training in Heart Failure}

training for a period of only 6 weeks. ${ }^{12,13}$ In the study by Bosnak-Guclu et al, ${ }^{16}$ both groups presented improvement in dyspnea following isolated IMT and concluded that higher workloads are necessary for their improvement.

When analyzing the IMT combined with another intervention compared with only performing another intervention, a small increase was observed, with no additional results in the other evaluated outcomes. Adamopoulos et $\mathrm{al}^{25}$ justify the lack of improvement in functional capacity with the addition of IMT to another intervention by the small diaphragmatic muscle training added to aerobic exercise and/or baseline functional status because the patients included had no serious impairment.

\section{Strengths and Limitations}

Our study presents a few strengths, such as a specific research question, comprehensive bibliographic search, explicit eligibility criteria, and meta-analysis. In addition, we evaluated some specific and important clinical questions regarding this type of intervention and for this type of population, which may directly interfere with the results found: IMT isolated or combined with another intervention; presence of inspiratory muscle weakness; training load; and intervention time. As limitations, we found that most RCTs were at high risk of bias, and the level of evidence for most outcomes was low or very low. This means that any estimate of effect is very uncertain, and it is very likely that new research will have an impact on the confidence to estimate the effect. ${ }^{35}$

\section{Comparisons With Other Reviews}

This review differs from the recent reviews published in 2018 by Wu et al $^{10}$ and Sadek et al, ${ }^{11}$ since the authors carried out the search only until the year 2016, included both RCTs and nonrandomized clinical trials, and did not perform all sensitivity analyzes observing the mentioned clinical issues cited above. Furthermore, Plentz et $\mathrm{al}^{9}$ and Sbruzzi et al $^{34}$ performed sensitivity analyses regarding the intervention time and the presence of respiratory muscle weakness. However, they excluded articles that associated IMT with another intervention and did not perform analyses in relation to the training load. Thus, this review addresses more complex and relevant issues for clinical practice.

Isolated IMT resulted in an increase in inspiratory muscle strength, functional capacity, and quality of life, and this increase was higher in studies that included patients with respiratory muscle weakness who used training loads higher than $60 \%$ and who had longer intervention times. The IMT, when performed in combination with another intervention, demonstrated only a small increase in respiratory muscle strength. So isolated IMT can be considered as an adjuvant intervention in patients with
HF, especially for patients who do not adhere to conventional rehabilitation.

\section{Author Contributions}

Concept/idea/research design: A.C.M. Azambuja, L.Z. de Oliveira, G. Sbruzzi

Writing: A.C.M. Azambuja, L.Z. de Oliveira, G. Sbruzzi

Data collection: A.C.M. Azambuja, L.Z. de Oliveira

Data analysis: A.C.M. Azambuja, L.Z. de Oliveira, G. Sbruzzi

Project management: A.C.M. Azambuja, G. Sbruzzi

Fund procurement: A.C.M. Azambuja

Providing participants: A.C.M. Azambuja

Consultation (including review of manuscript before submitting):

A.C.M. Azambuja, L.Z. de Oliveira, G. Sbruzzi

\section{Funding}

This study was funded in part by the Coordenação de Aperfeiçoamento de Pessoal de Nivel Superior.

\section{Systematic Review Registration}

This protocol was registered in PROSPERO (CRD42017080339).

\section{Disclosures}

The authors completed the ICMJE Form for Disclosure of Potential Conflicts of Interest and reported no conflicts of interest.

This study is linked to the Postgraduate Program in Pneumological Sciences and Postgraduate Program in Human Movement Sciences of the Universidade Federal do Rio Grande do Sul.

DOI: $10.1093 / p t j / p z a a 171$

\section{References}

1 Benjamin EJ, Virani SS, Callaway CW, et al. Heart disease and stroke statistics: 2018 update-a report from the American Heart Association. Circulation. 2018;137:e67-e492.

2 Meyer FJ, Borst MM, Zugck C, et al. Respiratory muscle dysfunction in congestive heart failure: clinical correlation and prognostic significance. Circulation. 2001;103:2153-2158.

3 Ramalho SHR, Cipriano G Jr, Vieira PJC, et al. Inspiratory muscle strength and six-minute walking distance in heart failure: prognostic utility in a 10 year follow up cohort study. PLoS One. 2019;14:e0220638.

4 Piepoli MF, Guazzi M, Boriani G, et al. Exercise intolerance in chronic heart failure: mechanisms and therapies. Part I. EurJ Cardiovasc Prev Rehabil. 2010;17:637-642.

5 Dhakal BP, Murphy RM, Lewis GD. Exercise oscillatory ventilation in heart failure. Trends Cardiovasc Med. 2012;22:185-191.

6 Ukkonen H, Burwash IG, Dafoe W, et al. Is ventilatory efficiency (VE/ $/ \mathrm{VCO}_{2}$ slope) associated with right ventricular oxidative metabolism in patients with congestive heart failure? Eur J Heart Fail. 2008;10:1117-1122.

7 Jaenisch RB, Bertagnolli M, Borghi-Silva A, Arena R, Lago PD. Respiratory muscle training improves diaphragm citrate synthase activity and hemodynamic function in rats with heart failure. Braz J Cardiovasc Surg. 2017;32:104-110.

8 Lin SJ, McElfresh J, Hall B, Bloom R, Farrell K. Inspiratory muscle training in patients with heart failure: a systematic review. Cardiopulm Phys Ther J. 2012;23:29-36. 
Inspiratory Muscle Training in Heart Failure

9 Plentz RD, Sbruzzi G, Ribeiro RA, Ferreira JB, Dal Lago P. Inspiratory muscle training in patients with heart failure: meta-analysis of randomized trials. Arq Bras Cardiol. 2012; 99:762-771.

10 Wu J, Kuang L, Fu L. Effects of inspiratory muscle training in chronic heart failure patients: a systematic review and meta-analysis. Congenit Heart Dis. 2018;13:194-202.

11 Sadek Z, Salami A, Joumaa WH, Awada C, Ahmaidi S, Ramadan W. Best mode of inspiratory muscle training in heart failure patients: a systematic review and meta-analysis. Eur J Prev Cardiol. 2018;25:1691-1701.

12 Higgins JPT, Thomas J, Chandler J, et al., eds.. Cochrane Handbook for Systematic Reviews of Interventions. Chichester, UK: John Wiley and Sons; 2011.

13 Robinson KA, Dickersin K. Development of a highly sensitive search strategy for the retrievel of reports of controlled trials using PubMed. Int J Epidemiol. 2002;31:150-153.

14 Dall'Ago P, Chiappa G, Guths H, Stein R, Ribeiro J. Inspiratory muscle training in patients with heart failure and inspiratory muscle weakness: a randomized trial. J Am Coll Cardiol. 2006; 47:757-763.

15 Stein R, Chiappa G, Güths H, Dall'Ago P, Ribeiro J. Inspiratory muscle training improves oxygen uptake efficiency slope in patients with chronic heart failure. J Cardiopulm Rehabil Prev. 2009;29:392-395.

16 Bosnak-Guclu M, Arikan H, Savci S, et al. Effects of inspiratory muscle training in patients with heart failure. Respir Med. 2011;105:1671-1681.

17 Johnson P, Cowley A, Kinnear W. A randomized controlled trial of inspiratory muscle training in stable chronic heart failure. Eur Heart J. 1998;19:1249-1253.

18 Marco E, Ramírez-Sarmiento A, Coloma A, et al. High-intensity vs. sham inspiratory muscle training in patients with chronic heart failure: a prospective randomized trial. Eur J Heart Fail. 2013;15:892-901.

19 Martínez A, Lisboa C, Jalil J, et al. Selective training of respiratory muscles in patients with chronic heart failure. Rev Med Chil. 2001;129:133-139.

20 Mello P, Guerra G, Borile S, et al. Inspiratory muscle training reduces sympathetic nervous activity and improves inspiratory muscle weakness and quality of life in patients with chronic heart failure: a clinical trial. J Cardiopulm Rehabil Prev. 2012;32:255-261.

21 Moreno AM, Toledo-Arruda AC, Lima JS, Duarte CS, Villacorta $\mathrm{H}$, Nobrega ACL. Inspiratory muscle training improves intercostal and forearm muscle oxygenation in patients with chronic heart failure: evidence of the origin of the respiratory metaboreflex. J Card Fail. 2017;23:672-679.

22 Padula C, Yeaw E, Mistry S. A home-based nurse-coached inspiratory muscle training intervention in heart failure. $A p p l$ Nurs Res. 2009;22:18-25.

23 Weiner P, Waizman J, Magadle R, Berar-Yanay N, Pelled B. The effect of specific inspiratory muscle training on the sensation of dyspnea and exercise tolerance in patients with congestive heart failure. Clin Cardiol. 1999;22: 727-732.

24 Laoutaris I, Dritsas A, Brown M, Manginas A, Alivizatos P, Cokkinos D. Inspiratory muscle training using an incremental endurance test alleviates dyspnea and improves functional status in patients with chronic heart failure. Eur J Cardiovasc Prev Rehabil. 2004;11:489-496.

25 Adamopoulos S, Schmid J, Dendale P, et al. Combined aerobic/inspiratory muscle training vs. aerobic training in patients with chronic heart failure: the Vent-HeFT trial-a European prospective multicentre randomized trial. Eur J Heart Fail. 2014;16:574-582.

26 Winkelmann ER, Chiappa GR, Lima COC, Viecili PRN, Stein R, Ribeiro JP. Addition of inspiratory muscle training to aerobic training improves cardiorespiratory responses to exercise in patients with heart failure and inspiratory muscle weakness. Am Heart J. 2009;158:768.e1-768.e7.

27 Kawauchi TS, Umeda IIK, Braga LM, et al. Is there any benefit using low-intensity inspiratory and peripheral muscle training in heart failure? A randomized clinical trial. Clin Res Cardiol. 2017;106:676-685.

28 Palau P, Domínguez E, López L, et al. Inspiratory muscle training and functional electrical stimulation for treatment of heart failure with preserved ejection fraction: the TRAINING-HF trial. Rev Esp Cardiol (Engl Ed). 2019;72: 288-297.

29 Tager T, Schell M, Cebola R, et al. Biological variation, reference change value (RCV) and minimal important difference (MID) of inspiratory muscle strength (PImax) in patients with stable chronic heart failure. Clin Res Cardiol. 2015;104:822-830.

30 Working Group on Cardiac Rehabilitation and Exercise Physiology and Working Group on Heart Failure of the European Society of Cardiology. Recommendations for exercise training in chronic heart failure patients. Eur Heart J. 2001;22:125-135.

31 Chiappa GR, Roseguini BT, Vieira PJ, et al. Inspiratory muscle training improves blood flow to resting and exercising limbs in patients with chronic heart failure. J Am Coll Cardiol. 2008; 51:1663-1671.

32 Miller JD, Smith CA, Hemauer SJ, Dempsey JA. The effects of inspiratory intrathoracic pressure production on the cardiovascular response to submaximal exercise in health and chronic heart failure. Am J Physiol Heart Circ Physiol. 2007; 292:H580-H592.

33 Tumminello G, Guazzi M, Lancellotti P, Pierard LA. Exercise ventilation inefficiency in heart failure: pathophysiological and clinical significance. Eur Heart J. 2007;28:673-678.

34 Sbruzzi G, Dal Lago P, Ribeiro RA, Plentz RD. Inspiratory muscle training and quality of life in patients with heart failure: systematic review of randomized trials. Int J Cardiol. 2012;156:120-121.

35 Guyatt GH, Oxman AD, Vist GE, et al. GRADE: an emerging consensus on rating quality of evidence and strength of recommendations. BMJ. 2008;336:924-926. 